\title{
Small high density lipoprotein subclasses: some of their physico-chemical properties and stability in solution ${ }^{\otimes}$
}

\author{
Ragheb F. Atmeh ${ }^{\bowtie}$ and Abd Elrazeq O. Issa \\ Department of Applied Chemical Sciences, University of Science and Technology, Irbed-JORDAN; \\ ${ }_{\text {e-mail: ragheb@just.edu.jo }}$
}

Received: 30 April, 2004; revised: 19 October, 2004; accepted: 15 December, 2004

available on-line: 31 May, 2005

\begin{abstract}
Small high density lipoproteins (SHDL) contribute to the protection from atherosclerosis, but detailed information about their properties is not available yet. We isolated four of the smallest HDL subclasses that contain apoA-I alone, the small lipoprotein A-I (SLpAI), by their separation on gradient polyacrylamide gel followed by electroelution. Their physico-chemical properties were calculated from their displacement in non-denaturing gradient polyacrylamide gel under the effect of electrical potential. The properties are: Stokes' radii 2.96-3.56 $\mathrm{nm}$; molecular masses 42-70 kDa; net negative charge 7.2-13.5; surface charge densities 3139-4069-esu $\cdot \mathrm{cm}^{-2}$; surface potentials 10.6-15.7 - $\mathrm{mV}$; coefficients of friction $5.74-6.90 \times 10^{-8} \mathrm{~g} \cdot \mathrm{s}^{-1}$; and diffusion coefficients $5.76-6.94 \times 10^{-7} \mathrm{~cm}^{2} \cdot \mathrm{s}^{-1}$. We found that these particles were of low stability as they underwent molecular transformation into larger particles on storage. The estimated dimensions of these particles do not support ellipsoidal shape, therefore, the most probable shape is spherical; consequently, their hydrated characteristics were estimated. We conclude that these particles have high values of negative surface charge and diffusion coefficients, and are of low stability. Their small Stokes' radii were similar to each other and they are spherical and highly hydrated.
\end{abstract}

Keywords: small high density lipoproteins, surface charge, diffusion coefficient, coefficient of friction, molecular shape, stability

Small high density lipoprotein (SHDL) particles are important because they act as acceptors of excess cholesterol from the peripheral body cells and deliver it to the liver in a process known as "reverse cholesterol transport" (Glomset, 1968). This process contributes to the prevention and regression of atherosclerosis where such particles should be of small size (Barter \& Connor, 1976) and contain ApoA-I, an activator of the enzyme lecithin:cholesterol acyltransferase (LCAT; Fielding \& Fielding, 1980; 1981); moreover, their charge characteristics are expected to affect their role (Braschi et al., 1999) as well as their clearance rate from circulation (Desrumaux et al., 1998). Recently, five discrete types of SHDL of molecular mass of 43-70 kDa were detected and quantitated in fresh plasma (Atmeh, 1990; Atmeh \& Robenek, 1996). The smallest three of these subclasses were shown to be of physiological relevance since their plasma level was affected by the physiological and pathological status of the subjects (Atmeh \& Robenek, 1996). Similar particles of small size were isolated by high-performance size exclusion chromatography (Nanjee \& Brinton, 2000) and by two dimensional gel electrophoresis (Castro \& Fielding, 1988) from healthy subjects, and by gradient polyacrylamide gel electrophoresis (gPAGE) in patients with LCAT deficiency (Chen et al., 1984). Other workers reported HDL subclasses of small size and of pre- $\beta$-electrophoretic mobility (relative to the electrophoretic migration of serum $\beta$-globulins) in isolated human HDL (Ishida et al., 1987) and in plasma (Sviridov et al., 2002). Many of the physico-chemical properties of the discrete SHDL particles have not been reported yet, and in order to better understand their metabolic role, their net charge and other physicochemical properties should

-Part of this work was presented at the 43rd International Conference on the Bioscience of Lipids, Graz, Austria, 11-14 September 2002.

Abbreviations: ApoA-I, apolipoprotein A-I, the major protein component of HDL; gPAGE, gradient polyacrylamide electrophoresis; HDL, high density lipoprotein; LCAT, lecithin;:cholesterol acyltransferase; POPC, palmitooleoylphosphatidylcholine; ; rHDL, reconstituted HDL; SHDL, small high density lipoprotein; SLpA, small lipoprotein A; VHDL, very high density lipoprotein. 
be determined. This will also aid in the design of protocols for their individual isolation and purification; a target that has not been achieved yet.

In this study we report the isolation, as a group, of four native discrete SHDL subclasses that contain apoA-I as the sole protein, the small lipoprotein A-I (SLpAI) group. To determine the net charge and other physicochemical properties of these particles we utilized their time-dependent migration in non-denaturing gradient polyacrylamide gel (gPAG) under the effect of electrical field. Moreover, we report here the low stability of these particles in vitro and present a prediction of the shape of the smallest particle.

\section{MATERIALS AND METHODS}

Subjects. Apparently healthy non-smoker subjects were studied. Due to the relatively low level of the SHDLs in the blood of fasting healthy subjects who do not drink alcohol, and in order to get reasonable amounts of the SHDLs for the study, blood was withdrawn $4 \mathrm{~h}$ after a breakfast meal rich in fat (Atmeh \& Robenek, 1996). As not all of the SHDL subclasses appear in the plasma of every subject, we analyzed individual samples from many subjects and choose 8 samples for each subclass and their average and S.E.M. were calculated. Venous blood was withdrawn into EDTA-containing tubes and plasma was isolated promptly by low-speed centrifugation at $4^{\circ} \mathrm{C}$ and gentamycin $\left(0.08 \mathrm{mg} \cdot \mathrm{mL}^{-1}\right)$, sodium azide $\left(0.1 \mathrm{mg} \cdot \mathrm{mL}^{-1}\right)$, and chloramphenicol $(0.08 \mathrm{mg}$ - $\mathrm{mL}^{-1}$ ) were added immediately.

Nomenclature. In previous work (Atmeh, 1990; Atmeh \& Robenek, 1996) five small HDL types of particles were reported with the molecular mass range of $43-70 \mathrm{kDa}$, and were shown to be present in both fresh plasma and in the isolated HDL fraction. The smallest three of them with molecular masses of 43-50 kDa were designated as SHDL (Atmeh \& Robenek, 1996). The fourth and fifth types had the same molecular mass of $70 \mathrm{kDa}$, and apoA-I was the sole apolipoprotein in one type, and both apoA-I and apoA-II were present in the other type with a molar ratio of 1:1 (Atmeh, 1990). For convenience, it would be reasonable to consider these types of particles as the small lipoprotein A (SLpA) group, and the particles that contain apoA-I alone as SLpAI and give the abbreviations SLp(AI+AII), SLpAI ${ }^{\prime}, \mathrm{SLpAI}_{2^{\prime}}$
$\mathrm{SLpAI}_{3}, \mathrm{SLpAI}_{4}$ for the individual types as detailed in Table 1.

Preparation of HDL and lipoprotein fraction of $d<1.22 \mathrm{~g} \cdot \mathrm{mL}^{-1}$. HDL $\left(d=1.063-1.22 \mathrm{~g} \cdot \mathrm{mL}^{-1}\right)$ was prepared by sequential ultracentrifugation at $10^{\circ} \mathrm{C}$ according to Havel et al. (1955) in a Beckman model L8-70M ultracentrifuge using a Beckman 50.3 Ti rotor (Beckman, Palo Alto, CA, USA). Similarly, lipoprotein fraction of $d<1.22 \mathrm{~g} \cdot \mathrm{mL}^{-1}$ was prepared by a single spin of plasma overnight. Both fractions were dialyzed against $0.15 \mathrm{M} \mathrm{NaCl}$ solution containing $0.01 \%$ EDTA for several hours. Both HDL and the lipoprotein fraction of $d<1.22 \mathrm{~g} \cdot \mathrm{mL}^{-1}$ were passed through an affinity chromatography column containing anti-albumin to remove any traces of albumin.

Nondenaturing gradient polyacrylamide gel electrophoresis (gPAGE). A 4-25\% gPAG was prepared and run as was described previously (Atmeh, 1990; Atmeh \& Abuharfeil, 1993). In brief, the gPAG was cast and run in an LKB 2001 vertical electrophoresis system (LKB, Sweden). An appropriate amount of lipoprotein was applied to each well of the gPAG and run at $15^{\circ} \mathrm{C}$ in Tris $(14 \mathrm{mM})$ and glycine $(110 \mathrm{mM})$ buffer, $\mathrm{pH}$ 8.3. The voltage gradient applied was $2542 \mathrm{~V} \cdot \mathrm{m}^{-1}$. Stokes' radius $\left(R_{s}\right)$ and relative molecular mass $\left(M_{\mathrm{r}}\right)$ were calculated in comparison with molecular weight markers (Sigma, St. Louis, MO, USA) of known Stokes' radius and molecular mass which were run in the same gel. After the run was complete, either the gel was stained and destained or treated as in the following section.

Electroelution of SLpA from the gradient gel. Freshly isolated lipoprotein fraction of $d<1.22$ $\mathrm{g} \cdot \mathrm{mL}^{-1}$ or HDL (300 $\mu \mathrm{g}$ protein) was separated on $4-25 \%$ gPAG and run as described in the above section. After the run was complete, the gel was cut longitudinally and the lane that contained the marker proteins was stained with Coomassie Brilliant Blue R-250 for a short time and the rest of the lanes were compared with the stained one in order to locate the position of individual lipoproteins. The gel portion that contained the required bands of molecular mass equal to or less than $70 \mathrm{kDa}$ (SLpA) was cut and placed in an electroelution apparatus developed by Atmeh (1989) and electroeluted as described elsewhere (Atmeh et al., 1991). The eluted SLpA fraction was tested by the double immunodiffusion technique using specific antibodies against albumin, apoC-I, apoC-II, and apoC-III. Since the subclasses

Table 1. Suggested abbreviations for small high density lipoprotein particles.

\begin{tabular}{|c|c|c|c|c|c|}
\hline \multirow[b]{3}{*}{ Reported particle } & \multicolumn{5}{|l|}{ SLpA } \\
\hline & \multicolumn{5}{|c|}{ SLpAI } \\
\hline & $(\mathrm{AI}+\mathrm{AII}) \mathrm{HDL}^{\mathrm{a}}$ & (AI)HDL & SHDL $^{b}$ & SHDL & SHDL \\
\hline Molecular mass (kDa) & 70 & 70 & 50 & 45 & 43 \\
\hline Suggested abbreviation & SLp(AI+AII) & $\mathrm{SLpAI}_{1}$ & $\mathrm{SLpAI}_{2}$ & $\mathrm{SLpAI}_{3}$ & $\mathrm{LpAI}_{4}$ \\
\hline
\end{tabular}

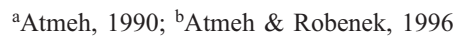


SLp(AI-AII) and SLpAI ${ }_{1}$ have the same molecular mass (Table 1) and migrate together (Atmeh, 1990), therefore, from now on we will confine our analysis to the $\mathrm{SLpAI}_{1}$ particle in addition to the other three.

Determination of migration distance $(D)$ and migration velocity $(V)$. The migration distance of each SLpAI type of particles in the $4-25 \%$ gPAG was measured at various time intervals $(1,2,4,8,12$, and $16 \mathrm{~h})$. Samples were applied to gradient gels and run, as described above, for the specified time interval followed by staining and destaining. The migration distance in millimetres $(D ; \mathrm{mm})$ and migration velocity $\left(V ; \mathrm{mm} \cdot \mathrm{s}^{-1}\right)$ of each SLpAI particle in each sample were measured. The migration behaviour of each lipoprotein was utilized to determine its maximum migration distance $\left(D_{\max }\right)$ and maximum gel concentration $\left(T_{\max }\right)$. The following parameters were calculated: coefficient of friction $(f)$, diffusion coefficient $\left(D_{c}\right)$, apparent electrophoretic mobility $(\mu)$, free electrophoretic mobility $(U)$, net negative charge $(Z)$, density of surface charge $\left(C_{d}\right)$, and surface potential $(S)$. The mathematical treatment reported by Rothe $(1991 ; 1994)$ that described some of those parameters was used. Following are the net equations that were used.

Determination of maximum migration distance $\left(D_{\max }\right)$. Migration distances $(D)$ of globular proteins in linear gPAG are not linearly correlated with time $(t)$ of electrophoresis nor with the reciprocal of time $\left(t^{-1}\right)$, therefore, this relation does not follow a simple hyperbolic function. Moreover, such distance and time are not related to the other by a simple exponential function. A linear relationship was found (Rothe, 1991) by plotting the double logarithm of $D,[\ln (\ln D)]$ versus the square root of $t^{-1}$, therefore, a straight line equation can be written as

$\ln (\ln D)=-\mathrm{a} t^{-1 / 2}+\mathrm{b}$

where $a$ and $b$ are the slope and intercept of the line, respectively, and can be determined from the plot of $\ln (\ln D)$ vs. $t^{-1 / 2}$. When the migration time $(t)$ approaches infinity, $t^{-1 / 2}$ approaches zero and the migration distance will approach the maximum migration distance $\left(D_{\max }\right)$ of the lipoprotein, thus $\ln \left(\ln D_{\max }\right)=\mathrm{b}$, consequently, $D_{\max }$ can be determined by extrapolating the straight line of Eqn 1 and measuring the intercept $b$.

Determination of gel concentration $(T)$ and maximum gel concentration $\left(T_{\max }\right)$. The gel concentration $(T ; \%)$ and the migration distance $(D ; \mathrm{mm})$ are linearly related by the following Eqn (Rothe, 1991):

$T=\alpha D+\beta$

where $\alpha$ is the slope of the line and $\beta$ is the starting (the lowest) concentration of the gradient gel. The value of the constant $\alpha$ was obtained from the scan at $405 \mathrm{~nm}$ of a $4-25 \%$ linear gradient PAG contain- ing $p$-nitrophenol (Rothe, 1991). These gels were prepared by adding the yellow-coloured $p$-nitrophenol $\left(0.075 \mathrm{mg} \cdot \mathrm{mL}^{-1}\right)$ to the concentrated $(25 \%)$ acrylamide solution during the preparation of the gel. The formed gel was scanned at $405 \mathrm{~nm}$ from top to bottom with correction for the absorbance of the supporting glass plate. The y-axis of the scan (absorbance) was related to the gel concentration where the top of the gel corresponds to the lower concentration of the gradient $(4 \%)$, and the bottom of the gel corresponds to the higher concentration of the gradient $(25 \%)$. The interval of the absorbance axis was divided into percentage concentration scale and for each point on the gel length (distance; $x$-axis), the corresponding $T(\%)$ value was obtained from the straight line of the scan. The slope of the line equals $\alpha$ and the intercept equals $\beta$, which is the lower gel concentration $(4 \%)$.

From Eqn (2) $D_{\max }$ can be written as

$D_{\text {max }}=\alpha^{-1}\left(T_{\max }-\beta\right)$

Determination of the apparent free electrophoretic mobility $(\mu)$. At polyacrylamide gel concentration of zero $(T=0)$, migration of a macromolecule is unhindered by the gel matrix and can be considered as migration in solution, i.e., the migration velocity is equivalent to the apparent free electrophoretic mobility $\left(\mu ; \mathrm{mm} \cdot \mathrm{s}^{-1}\right)$. The migration velocity is the rate of migration and equals:

$V\left(\mathrm{~mm} \cdot \mathrm{s}^{-1}\right)=\Delta D(\mathrm{~mm}) / \Delta t$

The relation between $V$ and $D$ is curvilinear and can be described by the following exponential equation (Rothe, 1991):

$V\left(\mathrm{~mm} \cdot \mathrm{s}^{-1}\right)=\varepsilon\left(D_{\max }-D\right)^{\delta}$

where $\varepsilon$ and $\delta$ are constants. Converting this equation into a logarithmic form we get a straight line equation:

$\ln V\left(\mathrm{~mm} \cdot \mathrm{s}^{-1}\right)=\delta \ln \left(D_{\max }-D\right)+\ln \varepsilon$

Plotting $\ln V\left(\mathrm{~m} \cdot \mathrm{m}^{-1}\right)$ vs. $\ln \left(D_{\max }-D\right)$, both $\delta$ and $\varepsilon$ can be determined. Substituting the values of $D$ and $D_{\max }$ with the corresponding values of $T$ and $T_{\text {max }}$ respectively, from equations (2) and (3) and rearrangement, we get:

$V\left(\mathrm{~mm} \cdot \mathrm{s}^{-1}\right)=\mathrm{h}\left(T_{\max }-T\right)^{\delta}$

where $h=\varepsilon \alpha^{-\delta}$. At $T=0$ we can write:

$\mu\left(\mathrm{mm} \cdot \mathrm{s}^{-1}\right)=V\left(\mathrm{~mm} \cdot \mathrm{s}^{-1}\right)=\mathrm{h}\left(T_{\max }-0\right)^{\delta}=\mathrm{h}\left(T_{\max }\right)^{\delta}$

thus $\mu$ can be calculated.

Determination of the free electrophoretic mobility $(U)$. The free electrophoretic mobility is defined as the apparent free electrophoretic mobility (in meters per second) relative to the electrophoretic potential ( $E$, voltage in volts/gel length in meters) applied, i.e., 
$U=\mu / E$ in $\mathrm{m}^{2} \cdot \mathrm{s}^{-1} \cdot \mathrm{V}^{-1}$

Calculation of the coefficient of friction $(f)$ and diffusion coefficient $\left(D_{c}\right)$. The coefficients of friction of SLpAI molecules were determined from the Stokes' equation:

$f=6 \pi \eta R_{s}$

and their diffusion coefficients were determined from the Stokes-Einstein equation:

$D_{c}=k_{\mathrm{B}} T / 6 \pi \eta R_{s}$

where $k_{\mathrm{B}}$ is Boltzmann constant, $T$ absolute temperature, and $\eta$ is the dynamic viscosity of the medium.

Calculation of the net negative charge $(Z)$. The number of unit charge was estimated from Debye-Hückel equation:

$U=\left(Z e / 6 \pi \eta R_{s}\right) \times F$

where $e$ is the unit charge and equals $1.602 \times 10^{-19}$ Coulomb; $F$ is a retardation factor which results from the electrophoretic effect where its value depends on $R_{s}$ and the composition and strength of the small ions of the buffer solution. The value of $F$ can be calculated from the equation:

$F=\left\{\mathrm{X}\left(\kappa R_{s}\right) / 1+\left(\kappa R_{s}\right)\right\}$

where $\kappa$ is related to the thickness of the ion layer around the macromolecule and equals the reciprocal of the radius of the ion cloud; $X\left(\kappa R_{s}\right)$ is the Henry's function.

Calculation of the density of surface charge $\left(C_{d}\right)$ and surface potential $(S)$. The density of surface charge in electrostatic units was calculated from the following relation (Sparks \& Phillips, 1992):

$C_{d}=3.82 \times 10^{-11} \mathrm{Z} / R_{s}^{2}$

The surface potential was calculated from Henry's equation:

$S=6 \pi \eta U / D$

where $D$ is the solvent dielectric constant.

Calculation of the partial specific volume [v(bar)] of SLpAI particles. The partial specific volume of the SLpAI particles can be calculated from the partial specific volumes of their components. Unfortunately, we are not able yet to isolate the individual SLpAI particles in a pure form and sufficient amount necessary for compositional analysis, therefore, we estimated their $v$ (bar) as follows. The molecular masses are 42, 45, 50, and $70 \mathrm{kDa}$ and each particle comprises one apoA-I molecule ( $v$ (bar) $0.736 \mathrm{~cm}^{3} \cdot \mathrm{g}^{-1}$; Vitello \& Scanu, 1976) and the rest of the mass is expected to be phospholipids and small amount of cholesterol with traces of triglycerides, if present. However, we assumed that the lipid moiety is mainly the phospholipid palmitooleoylphosphatidylcholine (POPC). Our assumption was based on the following findings: 1) Dergunov et al. (2001) found that the dimensions of reconstituted HDL (rHDL) particles did not change significantly in the presence or absence of cholesterol; 2) the size of the phospholipid bilayers does not change significantly in the presence or absence of cholesterol (Schwartz \& Paltauf, 1976; Tu et al., 1998) or if saturated or unsaturated fatty acids are present in the phospholipid (Armen et al., 1998; Chiu et al., 1999); 3) in similar spherical small HDL particles, apoA-I and phospholipid components represent more than $90 \%$ of the particle volume (Chen et al., 1984). The POPC $v$ (bar) value of $1.006 \mathrm{~cm}^{3} \cdot \mathrm{g}^{-1}$ was calculated from its molecular volume $\left(1263 \mathrm{~nm}^{3}\right)$ reported by Chiu et al (1990) using the formula reported by Tristram-Nagle et al. (1998).

Calculation of the lengths of the axes of SLpAI particles as ellipsoids. The values of the long axis (2a) and the short axis (2b) as well as the axial ratio $(a / b)$ of the ellipsoidal particles were predicted by the UltraScan software (Borries Demeler, $\mathrm{PhD}$, University of Texas Health Science Center at San Antonio, USA). The software utilizes the linear Lamm equation (Lamm, 1929) model for the analysis of ultracentrifugation and other molecular parameters (Demeler \& Saber, 1998).

Calculation of the radius of unhydrated spherical SLpAI particles $\left(\boldsymbol{R}_{o}\right)$. The volume of one mole of a spherical particle equals the product of its molecular mass by its partial specific volume, and the volume of one molecule is obtained on dividing the product by Avogadro's number $(\mathrm{N})$, or calculated from its radius $\left(R_{0}\right)$, i.e.,

volume of one molecule $=M_{r} v$ (bar) $/ \mathrm{N}=4 \pi R_{o}^{3} / 3$ (16)

Thus the value of $R_{o}$ can be written as:

$R_{o}=\left\{3 M_{r} v(\text { bar }) / 4 \pi \mathrm{N}\right\}^{1 / 3}$

Calculation of the coefficient of friction of spherical unhydrated SLpAI particles $\left(f_{o}\right)$, their frictional ratio $\left(f f_{o}^{-1}\right)$, and their sedimentation coefficient (s). These values were calculated by the above mentioned UltraScan software.

Calculation of the hydration properties of SLpAI particles. The radius and size of hydrated SLpAI particles are larger than those of unhydrated ones due to the presence of the hydration layer, therefore the hydration factor $(\delta ; g$ of water/g of lipoprotein) can be introduced into Eqn 17 which will be written as:

$R_{s}=\left\{\left[3 M_{r} / 4 \pi \mathrm{N}\right]\left[v(\text { bar })+\delta v_{o}(\text { bar })\right]\right\}^{1 / 3}$

where $v_{0}$ (bar) is the partial specific volume of water and approximately equals 1 .

The difference between the radius of a hydrated $\left(R_{s}\right)$ and that of an unhydrated spherical particle $\left(R_{0}\right)$ was used to calculate the thickness of hydration water around each SLpAI particle. Dividing the resulted value by $0.28 \mathrm{~nm}$ (thickness of one water 
layer) gave the number of hydration layers around the particle. The number of bound water molecules around each particle was calculated from the product of $\delta M_{\mathrm{r}}$ divided by 18 (the molar mass of water).

In vitro stability of SLpAI particles. To investigate the effect of storage on the stability of the isolated SLpA fraction, it was incubated with and without 5,5-dithiobis(2-nitrobenzoic acid) (an LCAT inhibitor), at $4^{\circ} \mathrm{C}$ for up to ten days followed by separation on $4-25 \%$ gPAGE.

\section{RESULTS}

The density of the Tris/glycine buffer and its viscosity at $20^{\circ} \mathrm{C}$ were $1.002 \mathrm{~g} \cdot \mathrm{cm}^{-3}$ and $0.01028 \mathrm{~g} \cdot$ $\mathrm{cm}^{-1} \cdot \mathrm{s}^{-1}$ (Poise), as measured by a pycnometer and Ostwald viscometer, respectively. The electroeluted SLpAI fraction was free from albumin and apoC-I, apoC-II, and apoC-III when tested against the corresponding specific antibody by the double immunodiffusion method. The SLpAI subclasses are shown in Fig. 1 before and after elution from gPAG.

\section{Migration distance $(D)$ and maximum migration distance $\left(D_{\max }\right)$}

The freshly isolated SLpA fraction from each sample (average $\mathrm{n}=8$ ) was run in duplicate on 4$25 \%$ gPAG for various time intervals. The values of $\ln (\ln D)$ were plotted against $t^{-1 / 2}$ according to Eqn 1 and the value of $D_{\max }$ for each type of particles was calculated from the intercept (Table 2).

Gel concentration ( $T$ ), and maximum gel concentration $\left(T_{\max }\right)$

The slope $(\alpha)$ of the straight line of Eqn 2 was 0.181 as calculated from the scanned gPAG con-

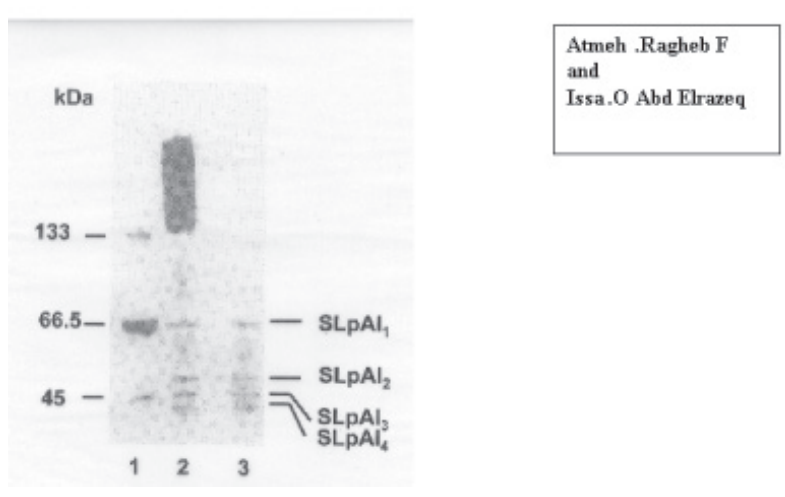

Figure 1. High density lipoprotein subclasses separated on $4-25 \%$ gPAGE.

Lane 1: molecular mass standards; lane 2: total HDL; lane 3: SLpAI subclasses; HDL was run on $4-25 \%$ gPAGE, the region containing the SLPAI was cut out, eluted and rerun on another $4-25 \%$ gPAGE.

taining $p$-nitrophenol. The value of the constant $(\beta)$ equals $4.0 \%$, which is the lower concentration of the gradient gel. Thus Eqn 2 will be:

$$
T(\%)=0.181 \times D(\mathrm{~mm})+4.0
$$

The values of $T_{\max }(\%)$ for each SLpAI particle were calculated from the corresponding $D_{\max }$ value (Table 2).

Migration velocity $(V)$, apparent free electrophoretic mobility $(\mu)$ and free electrophoretic mobility $(U)$

The migration velocity for each type of particles at each time point was calculated from equation 4 , and plotting the values of $\ln V$ versus $\ln \left(D_{\max }-D\right)$ (Eqn 6) enabled the calculation of the constants $\varepsilon$ and $\delta$ which were used to calculate the value of the constant $h$. The values of $\mu$ and $U$ were calculated from Eqns 8 and 9, respectively (Table 2).

Table 2. Calculated physico-chemical properties of the SLpAI particles from their measured electrophoretic migration behaviour.

Electrophoresis was done in 4-25\% gPAG for various time intervals and the voltage gradient used was $2542 \mathrm{~V} \cdot \mathrm{m}^{-1}$.

\begin{tabular}{lcccc}
\hline Parameter & $\mathrm{SLpAI}_{1}$ & $\mathrm{SLpAI}_{2}$ & $\mathrm{SLpAI}_{3}$ & $\mathrm{SLpAI}_{4}$ \\
\hline$D_{\max }(\mathrm{mm})$ & $154.2 \pm 3.0^{\mathrm{a}}$ & $183.5 \pm 2.6$ & $204.9 \pm 3.8$ & $216.2 \pm 1.9$ \\
$T_{\max }(\%)$ & $31.9 \pm 0.6$ & $37.2 \pm 0.5$ & $41.1 \pm 0.7$ & $43.1 \pm 0.3$ \\
$\mu \times 10^{6}\left(\mathrm{~m} \cdot \mathrm{s}^{-1}\right)$ & $18.32 \pm 1.2$ & $13.65 \pm 0.5$ & $13.39 \pm 0.7$ & $12.43 \pm 0.3$ \\
$U \times 10^{9}\left(\mathrm{~m}^{2} \cdot \mathrm{s}^{-1} \cdot \mathrm{V}^{-1}\right)$ & $7.21 \pm 0.5$ & $5.37 \pm 0.2$ & $5.27 \pm 0.3$ & $4.89 \pm 0.1$ \\
$R_{s} \times 10^{9}(\mathrm{~m})$ & $3.56 \pm 0.01$ & $3.22 \pm 0.01$ & $3.06 \pm 0.01$ & $2.96 \pm 0.01$ \\
Molecular mass $(\mathrm{kDa})$ & $70 \pm 0.5$ & $50 \pm 0.7$ & $45 \pm 0.8$ & $42 \pm 0.9$ \\
$D_{c} \times 10^{7}\left(\mathrm{~cm}^{2} \cdot \mathrm{s}^{-1}\right)$ & $5.76 \pm 0.03$ & $6.37 \pm 0.03$ & $6.70 \pm 0.04$ & $6.94 \pm 0.04$ \\
$f \times 10^{8}\left(\mathrm{~g} \cdot \mathrm{s}^{-1}\right)$ & $6.90 \pm 0.02$ & $6.24 \pm 0.02$ & $5.93 \pm 0.02$ & $5.74 \pm 0.02$ \\
$Z(-\mathrm{e})$ & $13.5 \pm 0.4$ & $9.0 \pm 0.4$ & $8.1 \pm 0.6$ & $7.2 \pm 0.5$ \\
$Z \times 10^{19}\left(\mathrm{Coulomb}^{2}\right.$ & $21.7 \pm 0.7$ & $14.4 \pm 0.6$ & $13.5 \pm 0.9$ & $11.7 \pm 0.9$ \\
$C_{d}\left(-\mathrm{esu} \cdot \mathrm{cm}^{-2}\right)$ & $4069 \pm 102$ & $3316 \pm 131$ & $3305 \pm 225$ & $3139 \pm 199$ \\
$S(-\mathrm{mV})$ & $15.7 \pm 0.1$ & $11.7 \pm 0.1$ & $11.4 \pm 0.2$ & $10.6 \pm 0.2$ \\
\hline
\end{tabular}


Table 3. Calculation of the partial specific volume $(v($ bar $))$ of the SLpAI particles from their theoretical composition.

\begin{tabular}{|c|c|c|c|c|}
\hline Parameter & $\mathrm{SLpAI}_{1}$ & $\mathrm{SLpAI}_{2}$ & $\mathrm{SLpAI}_{3}$ & $\mathrm{SLpAI}_{4}$ \\
\hline Molecular mass (kDa) & 70 & 50 & 45 & 42 \\
\hline Number of apolipoprotein molecules per particle & $1 \mathrm{~A}-\mathrm{I}$ & 1 A-I & $1 \mathrm{~A}-\mathrm{I}$ & $1 \mathrm{~A}-\mathrm{I}$ \\
\hline Mass of apolipoprotein (kDa) & 28 & 28 & 28 & 28 \\
\hline Percentage of protein & 40.0 & 56.0 & 62.2 & 66.7 \\
\hline Volume of protein in one gram of lipoprotein $\left(\mathrm{cm}^{3}\right)$ & $0.236^{\mathrm{a}}$ & 0.412 & 0.458 & 0.491 \\
\hline Percentage of lipids & 60.0 & 44.0 & 37.8 & 33.3 \\
\hline Volume of phospholipids in one gram lipoprotein $\left(\mathrm{cm}^{3}\right)$ & $0.604^{\mathrm{b}}$ & 0.443 & 0.380 & 0.335 \\
\hline Partial specific volume; $\mathrm{v}(\mathrm{bar})\left(\mathrm{cm}^{3} \cdot \mathrm{g}^{-1}\right)$ & 0.840 & 0.855 & 0.838 & 0.826 \\
\hline
\end{tabular}

a $v$ (bar) for apoA-I is $0.736 \mathrm{~cm}^{3} \cdot \mathrm{g}^{-1}$ (Vitello \& Scanu, 1976); ${ }^{\mathrm{b}} v\left(\right.$ bar) for POPC is $1.006 \mathrm{~cm}^{3} \cdot \mathrm{g}^{-1}$ (as calculated from Tristram-Nagle et al., 1998; Chiu et al., 1999)

Stokes' radius $\left(R_{s}\right)$, molecular mass diffusion coefficient $\left(D_{c}\right)$, and charge characteristics

The plot of $\ln R_{\mathrm{s}}$ vs $\ln D_{\max }$ for the marker proteins was linear, and from this plot the $R_{\mathrm{s}}$ of the SLpAI subclasses were obtained and found to be in the range $2.96-3.56 \mathrm{~nm}$. The molecular mass was determined in a similar manner and was found in the range $42-70 \mathrm{kDa}$. The value of the diffusion $\mathrm{co}^{-}$ efficient $\left(D_{c}\right)$ was calculated from Eqn 11 and was found to be in the range 5.76-6.94 $\times 10^{-7} \mathrm{~cm}^{2} \cdot \mathrm{s}^{-1}$. The quantities $Z, C d$, and $S$ were calculated from Eqns 12, 14, and 15, respectively. All these values are shown in Table 2.

\section{Radius and volume of SLpAI particles}

The partial specific volumes of $\mathrm{SLpAI}_{1-4}$ were calculated as $0.840,0.855,0.838$, and $0.826 \mathrm{~cm}^{3} \cdot \mathrm{g}^{-1}$, respectively (Table 3$)$. These values are less than that reported by Patsch et al. (1980) for a high density lipoprotein fraction with molecular mass of $152 \mathrm{kDa}$ designated as $\mathrm{HDL}_{\mathrm{i}}\left(0.961 \mathrm{~cm}^{3} \cdot \mathrm{g}^{-1}\right)$. From these values and the relative molecular masses of $\mathrm{SLpAI}_{1-4}$ we predicted the lengths of their axes by the software UltraScan (Table 4). The length of the shorter axis (2b) of the particles was $1.74,1.54,1.52$, and $1.50 \mathrm{~nm}$ as oblate ellipsoids (discs). These values are much shorter than the thickness of a phospholipid bilayer (3.5 nm; Tristram-Nagle et al., 1998; Brouillette et al., 2001; Rog et al., 2003) which excludes the possibility of the particles being ellipsoids. This renders the sphere as the probable shape of the particles. The ellipsoidal shape can be further excluded by calculating the circumferences of the assumed discoidal particles from their phospholipid content. The calculated circumferences of the $\mathrm{SLpAI}_{1-4}$ particles were $14.83,10.69,9.49$, and $8.55 \mathrm{~nm}$, respectively (Table $5)$. These circumference lengths are much shorter than the length of one apoA-I helical molecule; this means that apoA-I will make more than one turn around these discs. Being spherical particles, their unhydrated radii were calculated from Eqn 17 from their corresponding $M_{r}$ and $v$ (bar) values and were found to be 2.85, 2.56, 2.46, and $2.39 \mathrm{~nm}$ (Table 6). The unhydrated and hydrated volumes were calculated from Eqn 16 using the corresponding $R_{o}$ and $R_{\mathrm{s}}$ values, respectively (Table 6).

Frictional coefficient $\left(f_{o}\right)$, frictional ratio $\left(f f_{o}^{-1}\right)$, and sedimentation coefficient $(s)$ of the unhydrated SLpAI particles

The calculated frictional coefficients of unhydrated particles were in the range 5.52-4.63 x $10^{-8} \mathrm{~g}$ . $\mathrm{s}^{-1}$, their frictional ratios were in the range 1.271.24 , and their sedimentation coefficients were in the range $2.74-1.94 \times 10^{-13} \mathrm{~s}$ (Table 6).

\section{Hydration properties of the SLpAI particles}

The calculated thickness of the hydration shell around the SLPAI particles was in the range 0.71-0.57 nm equivalent to 2.5-2.0 layers of water comprising 3100-1700 water molecules (Table 6).

\section{In vitro stability of SLpA particles}

When the isolated SLpA subclasses were incubated at $4^{\circ} \mathrm{C}$, in the presence or absence of an LCAT

Table 4. Molecular dimensions of SLpAI particles as oblate ellipsoids predicted by the UltraScan software (UTHSCSA).

\begin{tabular}{lcccc}
\hline Parameter & $\mathrm{SLpAI}_{1}$ & $\mathrm{SLpAI}_{2}$ & $\mathrm{SLpAI}_{3}$ & $\mathrm{SLpAI}_{4}$ \\
\hline a (long axis) $(\mathrm{nm})$ & 5.13 & 4.67 & 4.43 & 4.26 \\
b (short axis) $(\mathrm{nm})$ & 0.87 & 0.77 & 0.76 & 0.75 \\
a/b ratio & 5.92 & 6.04 & 5.86 & 5.66 \\
Volume $\left(\mathrm{nm}^{3}\right)$ & 96.8 & 70.6 & 62.0 & 57.2 \\
\hline
\end{tabular}


Table 5. Calculated circumferences of discoidal SLpAI particles.

\begin{tabular}{|c|c|c|c|c|c|c|}
\hline Particle & $\begin{array}{l}\text { Lipid } \\
\text { mass } \\
(\mathrm{kDa})\end{array}$ & $\begin{array}{l}\text { No. of POPC } \\
\text { molecules in the } \\
\text { particle }\end{array}$ & $\begin{array}{l}\text { No. of POPC mole- } \\
\text { cules in each phos- } \\
\text { pholipid layer }\end{array}$ & $\begin{array}{l}\text { Surface area of the } \\
\text { circular leaflet face } \\
\left(\mathrm{nm}^{2}\right)\end{array}$ & $\begin{array}{l}\text { Radius of the } \\
\text { leaflet face } \\
(\mathrm{nm})\end{array}$ & $\begin{array}{l}\text { Circumference of } \\
\text { the particle } \\
(\mathrm{nm})\end{array}$ \\
\hline $\mathrm{SLpAI}_{1}$ & $42^{\mathrm{a}}$ & $55^{\mathrm{b}}$ & $27^{c}$ & $17.55^{\mathrm{d}}$ & $2.36^{\mathrm{e}}$ & $14.83^{\mathrm{f}}$ \\
\hline $\mathrm{SLpAI}_{2}$ & 22 & 29 & 14 & 9.10 & 1.70 & 10.69 \\
\hline $\mathrm{SLpAI}_{3}$ & 17 & 22 & 11 & 7.15 & 1.51 & 6.49 \\
\hline $\mathrm{SLpAI}_{4}$ & 14 & 18 & 9 & 5.85 & 1.36 & 8.55 \\
\hline
\end{tabular}

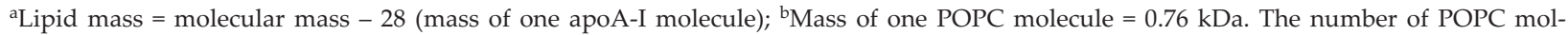
ecules in each particle is obtained by dividing the mass of the particle by the mass of POPC molecule. ${ }^{\mathrm{N}} \mathrm{Number}$ of POPC molecules in each phospholipid layer $=1 / 2$ the number of POPC molecules in the particle. ${ }^{\mathrm{d}}$ Surface area of one POPC $=0.65 \mathrm{~nm}^{2}(\mathrm{Murzyn}$ et al., 2001 ; Koln et al., 2002). The surface area of the circular leaflet face of the particle $=$ number of POPC molecules $\times 0.65$. eSurface area of the circular leaflet face of the particle $=\pi r^{2}$, therefore, $r$ can be calculated. ${ }^{\mathrm{f} C i r c u m f e r e n c e ~ o f ~ t h e ~ d i s c o i d a l ~ p a r t i c l e ~}=2 \pi r$.

inhibitor, for 1,2 , and 3 days followed by separation on a gradient gel, no detectable change regarding the number and position of bands was observed after their separation on the gradient gel. On the other hand, incubation at $4^{\circ} \mathrm{C}$, in the presence or absence of an LCAT inhibitor, for 10 days showed the presence of at least twelve bands of molecular masses ranging from 41 to $504 \mathrm{kDa}$ (Table 7). Some samples showed a band of molecular mass around $28 \mathrm{kDa}$ which is expected to be the lipid free apoA-I.

\section{DISCUSSION}

SLpAI particles are important because they are the initiators of the reverse cholesterol transport process (Miller, 1990; Chiesa et al., 1998; Gillotte et al., 1998), but not much is known about their physico-chemical and metabolic properties. Therefore, further investigation of their properties contributes to the better understanding of their individual metabolism and physiological function (Davidson et al., 1995; Colvin \& Parks, 1999). Such physiological role is a function of small size (Oram et al., 1981; Dory et al., 1986), high negative charge (Desrumaux et al., 1989; Dory et al., 1986; Sparks et al., 1995; Saku et al., 1999), high diffusion (Castro \& Fielding, 1988), and low thermodynamic stability (Sparks et al., 1999) of the particles. The physico-chemical properties of macromolecules are commonly determined from the study of their displacement in solution by the effect of an external gradient of a potential caused by either electrical (electrophoresis) or gravitational (sedimentation) forces (Giddings, 1991). Isolation of the individual SLpAI particles in reasonable purity and significant amounts has not been achieved yet, due to the minor differences in their size and molecular mass, which has hindered the determination of their physico-chemical properties. In order to overcome this problem we isolated the four SLPAI particles as a group and studied their displacement in gradient polyacrylamide gel by the effect of electrical potential, and the migration behaviour of each type of these particles was followed. The migration distances at various time intervals were measured and used for the determination of the maximum migration distance $\left(D_{\max }\right)$ that each particle can migrate in the gradient gel at time infinity. The $D_{\max }$ value of the SLpAI particles increased with the decrease in particle size and ranged from 154.2 to $216.2 \mathrm{~mm}$ (Table 2). Since the migration is in a gradient gel, then $D_{\max }$ depends on the particle dimensions that correspond to the gel pore size. From the knowledge of the gel concentration $(T \%)$ at each point

Table 6. Calculated molecular dimensions, frictional and hydration characteristics, and sedimentation coefficients of the spherical SLpAI particles.

\begin{tabular}{|c|c|c|c|c|}
\hline Parameter & $\mathrm{SLpAI}_{1}$ & $\mathrm{SLpAI}_{2}$ & $\mathrm{SLpAI}_{3}$ & $\mathrm{SLpAI}_{4}$ \\
\hline$R_{o}$ (unhydrated) (nm) & 2.85 & 2.56 & 2.46 & 2.39 \\
\hline Volume (unhydrated) $\left(\mathrm{nm}^{3}\right)$ & 96.8 & 70.3 & 62.4 & 57.2 \\
\hline Volume (hydrated) $\left(\mathrm{nm}^{3}\right)$ & 189.0 & 139.9 & 120.0 & 108.6 \\
\hline$f_{o} \times 10^{8}\left(\mathrm{~g} \cdot \mathrm{s}^{-1}\right)^{\mathrm{a}}$ & 5.52 & 4.96 & 4.77 & 4.63 \\
\hline$f f_{0}^{-1}$ & 1.27 & 1.26 & 1.24 & 1.24 \\
\hline Thickness of water of hydration ${ }^{\mathrm{b}}(\mathrm{nm})$ & 0.71 & 0.66 & 0.60 & 0.57 \\
\hline Number of hydration layers & 2.5 & 2.4 & 2.1 & 2.0 \\
\hline $\begin{array}{l}\text { Number of water molecules bound to one } \\
\text { SLpAI molecule }\end{array}$ & 3100 & 2300 & 2000 & 1700 \\
\hline Hydration factor $(\delta)$ (g water/g SLpAI) & 0.80 & 0.83 & 0.78 & 0.74 \\
\hline Sedimentation coefficient $(s) \times 10^{13} \mathrm{~s}$ & 2.74 & 1.94 & 2.08 & 2.13 \\
\hline
\end{tabular}

${ }^{\mathrm{a}} f_{o}=6 \pi \eta R_{\sigma^{\prime}}{ }^{\mathrm{b}}=R_{s}-R_{o}$ 
Table 7. Molecular masses of SLpA transformation products.

SLpA were isolated by electroelution from $4-25 \%$ gradient polyacrylamide gel on which HDL was separated. The isolated SLpA fraction was incubated at $4^{\circ} \mathrm{C}$ for 10 days followed by separation on similar gradient polyacrylamide gel.

\begin{tabular}{lllllllllllll}
\hline Band number & 1 & 2 & 3 & 4 & 5 & 6 & 7 & 8 & 9 & 10 & 11 & 12 \\
\hline Molecular mass (kDa) & 41 & 51 & 55 & 75 & 89 & 103 & 121 & 145 & 166 & 193 & 287 & 504 \\
\hline
\end{tabular}

along the gradient gel, a certain gel concentration value $\left(T_{\max }\right)$ was obtained for each particle (Table 2$)$ at its corresponding $D_{\max }$ value, where beyond this value it cannot migrate. The migration velocity for each type of particles was calculated from the corresponding value of $T_{\max }$ (Eqn 7 ), and this velocity at zero gel concentration represents the apparent free electrophoretic mobility $(\mu)$ which was used to calculate the free electrophoretic mobility $(U)$ (Table 2). Comparing our measured $U$ values for SLpA-I $\mathrm{I}_{1-4}$ with high density lipoproteins of larger size (HDL and VHDL as reported by Sparks \& Phillips, 1992) of Stokes' radii of 4.5 and $3.8 \mathrm{~nm}$, respectively, we found that the free electrophoretic mobility of SLpA$\mathrm{I}_{1}\left(7.21 \mathrm{~m}^{2} \cdot \mathrm{s}^{-1} \cdot \mathrm{V}^{-1}\right)$ is larger than that of both $\mathrm{HDL}_{3}$ and VHDL (5.9 and $6.2 \mathrm{~m}^{2} \cdot \mathrm{s}^{-1} \cdot \mathrm{V}^{-1}$, respectively), whereas the $U$ values for SLpA- $I_{2-4}$ are smaller. This is in accordance with the values of the net charge (Z) of the particles which was -13.5 for SLpA- $\mathrm{I}_{1}$ and - 11.5 and -9.0 for $\mathrm{HDL}_{3}$ and VHDL, respectively, and -9.0 to -7.2 for SLpA-I $\mathrm{I}_{2-4}$. Similarly, the surface potential values of SLpA-I $(-13.5 \mathrm{mV})$ and SLpA-I $\mathrm{I}_{2-4}$ $(-11.7$ to $-10.6 \mathrm{mV})$ were higher and lower, respectively, than those of $\mathrm{HDL}_{3}$ and VHDL (-11.5 and - $11.9 \mathrm{mV}$, respectively). However, the reported values of the surface charge of $\mathrm{HDL}_{3}$ and VHDL (2220 and $1800-\mathrm{esu} \cdot \mathrm{cm}^{-2}$; Sparks \& Phillips, 1992) were lower than our values for SLpA-I ${ }_{1-4}$ (4069-3139 -esu $\cdot \mathrm{cm}^{-2}$ ). Moreover, a comparison of the charge characteristics of SLpA-I ${ }_{1-4}$ with those of pure apoA-I (U: $4.3 \mathrm{~m}^{2} \cdot \mathrm{s}^{-1} \cdot \mathrm{V}^{-1}, \mathrm{Z}:-3.7, \mathrm{~S}:-8.3 \mathrm{mV}$, and $C_{d}: 1800$ - esu $\cdot \mathrm{cm}^{-2}$; Sparks \& Phillips, 1992) shows that these values of apoA-I are less than those of SLpA$\mathrm{I}_{1-4}$ (Table 2). This increase in the charge characteristics of SLpA-I $\mathrm{I}_{1-4}$ more than those of pure apoA-I can be explained by changes in apoA-I conformation that result from its binding with lipids to form lipoproteins, where different domains are exposed, and this exposure is a function of the size and lipid content of the particles (Petit et al., 1987; Pio et al., 1988; Marcovina et al., 1990; Collet et al., 1991; Fielding et al., 1994; Tricerri et al., 1998). In the light of these findings, the presence of several SLpA-I particles with varying physico-chemical properties can be easily understood. In accordance with that, Sparks et al. (1992a; 1992b) showed that different HDL subspecies maintain particular apoA-I conformations that confer unique charge and structural characteristics on the particles. The presence of several discrete particles of SLpA in blood with varying physico-chemi- cal properties may imply different roles both in lipid transport and in other physiological processes, and we can speculate that they may have different origins, functions, and/or fates. Recently, similar small particles were proposed to have a role in the regulation of human placental lactogen during pregnancy (Handwerger et al., 1999). Moreover, the differences in their properties may imply an involvement as cholesterol acceptors in various efflux mechanisms or preferential removal of cholesterol from different types of tissue cells (Rothblat et al., 1999; Haynes et al., 2000). The relative importance of each efflux mechanism would be determined by the cell type, metabolic status, tissue location, and the nature of the extracellular cholesterol acceptor (Rothblat et al., 1999). The diffusion coefficients of the SLpAI particles were high, which is a requirement for these particles to approach the aqueous environment of the peripheral cells and come in close contact with them in order to initiate the process of cholesterol removal from these cells (Castro \& Fielding, 1988).

Regarding the size of those discrete SLpA-I particles, they are smaller than the reported discrete high density lipoproteins. Several workers reported the following particles of Stokes' radii: Sm-LpA-I, $3.75 \mathrm{~nm}$ (Duverger et al., 1993) and $3.8 \mathrm{~nm}$ (Ohta et al., 1995); $\mathrm{HDL}_{3 c^{\prime}} 3.81 \mathrm{~nm}$ (Blanche et al., 1981); LpAI, 3.8-3.9 nm (Cheung \& Albers, 1984); $\mathrm{HDL}_{14^{\prime}}<3.93$ nm (Li et al., 1994).

HDL particles are either spherical or ellipsoidal in shape; and in order to predict the shape of the SLpAI particles we estimated their axial lengths as oblate ellipsoids. The estimated values did not produce reasonable dimensions for the ellipsoids, and the calculated circumferences were much shorter than the length of one apoA-I helix. This result looks logical in the light of the small number of lipid molecules in the particles. The spherical shape of such small particles is more probable and may be more stable especially if neutral lipids are present. Indeed, Jonas et al. (1990) reported that apoA-I in spherical rHDL is more stable than in a discoidal one, suggesting a more stable interaction of the $\alpha$ helical segment of apoA-I with lipid in the spherical particles. The presence of neutral lipids in small HDL particles was reported by many workers. Atmeh (1990) reported the presence of neutral lipids in the $70 \mathrm{kDa}$ SHDL subclass, and Chen et al. (1984) described a spherical particle of about $83 \mathrm{kDa}$ that contained 4.5 mole \% non-polar lipids. Moreover, 
Nanjee and Brinton (2000) reported a spherical shape of small HDL particles of 40-60 kDa, and Jaspard et al. (1996) reported a spherical shape for the small particle pre- $\beta_{1}$ HDL that contained $9 \%$ of its total mass as non-polar lipids. Considering the spherical shape of SLpAI particles, we calculated their hydration properties and found that their frictional ratios were 1.27-1.24 and the molecules were surrounded by 2.0-2.5 layers of hydration water (Table 6). A frictional ratio of more than one indicates either a non-spherical particle or a hydrated spherical particle. The first possibility was excluded as discussed above, therefore, the second possibility supports the spherical shape.

Lipidation of apoA-I to form small recombinant HDL particles is associated with decreased thermodynamic stability that may contribute to the metabolic reactivity of similar particles. This enhances their ability to accept cholesterol from cells and subsequent conversion into more stable larger particles (Sparks et al., 1999). In agreement with that we found that the pure isolated SLpA particles were stable at $4^{\circ} \mathrm{C}$ for three days, but they were not stable on storage for longer periods of time (10 days) and a large number of particles of increasing molecular mass were detected (Table 7). This interconversion occurred in the absence of the enzyme LCAT because the solution contained pure electroeluted SLpA particles; with that, the incubation was done in the presence or absence of 5,5'-dithiobis(2-nitrobenzoic acid), an LCAT inhibitor. In support of that, Chen et al. (1984) reported low stability of small HDL particles of $2.99 \mathrm{~nm}$ radius where they decomposed and formed larger and smaller particles. The large particles may have been formed by either self-association or fusion of different SLpA particles. In accordance with that, Lusa et al. (1996) reported HDL fusion that involved the formation of unstable intermediate HDL particles. Castro and Fielding (1988) explained the presence of a large HDL subclass (LpA-I $\left.\mathrm{p}_{\text {pre- } \beta 2}\right)$, of molecular mass of $325 \mathrm{kDa}$ in an incubation mixture, as a result of fusion of smaller particle (LpA-I ${ }_{\text {pre- } \beta 1}$ ) of molecular mass of $71 \mathrm{kDa}$.

For a better understanding of the physiological function of apoA-I-containing lipoproteins, it is important to study the conformation of apoA-I in the native lipid-bound state rather than in rHDL particles. This requires the isolation of individual native discrete apoA-I-containing lipoprotein particles, a target that has not been achieved yet. This problem was addressed by Phillips et al. (1997) where they stated: "So far, the structure of apoA-I in native lipoproteins has not been amenable to study, as it exists in very heterogeneous particles and, possibly, in diverse conformations. Reconstituted HDL, of defined compositions and sizes, has provided the best opportunities to learn about the structure-function relationships of apoA-I"'. We here present a study of native discrete small HDL particles, and we are in the process of attempting their individual isolation. This will offer a good opportunity for the study of the structure and conformations of apoA-I in native, not reconstituted, lipoproteins.

\section{Acknowledgements}

This work was supported by grant No. 17/99 from the Research Council of the Jordan University of Science and Technology.

\section{REFERENCES}

Armen R, Uitto OD, Feller SE (1998) Phospholipid component volumes: determination and application to bilayer structure calculations. Biophys J 75: 734-744.

Atmeh RF (1989) Concentration of dilute solutions of macromolecules by electrophoresis. Anal Biochem 182: 315318.

Atmeh RF (1990) Isolation and identification of HDL particles of low molecular weight. J Lipid Res 31: 17711780 .

Atmeh RF, Abuharfeil N (1993) Electroblotting of proteins on agarose gel containing specific antibodies. Electrophoresis 14: 69-72.

Atmeh RF, Robenek H (1996) Measurement of small high density lipoprotein subclass by an improved immunoblotting technique. J Lipid Res 37: 2461-2469.

Atmeh RF, Abuharfeil NM, Al-Sukhon SN, Abo-Shehada MN (1991) Electrophoretic elution of macromolecules from polyacrylamide or agarose gels. Prep Biochem 21: $1-9$.

Barter PJ, Connor WE (1976) The transport of esterified cholesterol in plasma high density lipoproteins of human subjects: a mathematical model. J Lab Clin Med 88: 627-639.

Blanche PJ, Gong EL, Forte TM, Nichols AV (1981) Characterization of human high density lipoproteins by gradient gel electrophoresis. Biochim Biophys Acta 665: 408-419.

Braschi S, Neville TA-M, Vohl M-C, Sparks DL (1999) Apolipoprotein A-I charge and conformation regulate the clearance of reconstituted high density lipoprotein in vivo. J Lipid Res 40: 522-532.

Brouillette CB, Anantharamaiah GM, Engler JA, Borhani DW (2001) Structural models of human apolipoprotein A-I: a critical analysis and review. Biochim Biophys Acta 1531: 4-46.

Castro GR, Fielding CJ (1988) Early incorporation of cellderived cholesterol into pre- $\beta$-migrating high density lipoprotein. Biochemistry 27: 25-29.

Chen C, Applegate K, King WC, Glomset JA, Norum KR, Gjone E (1984) A study of the small spherical high density lipoproteins of patients afflicted with familial lecithin:cholesterol acyltransferase deficiency. J Lipid Res 25: 269-282.

Cheung MC, Albers JJ (1984) Characterization of lipoprotein particles isolated by immuno-affinity chromatography, particles containing A-I and A-II and particles containing A-I but no A-II. J Biol Chem 259: 1220112209.

Chiesa G, Parolini C, Canvesi M, Colombo N, Sirtori CR, Fumagalli R, Franceschini G, Bernini F (1998) Human apolipoproteins A-I and A-II in cell cholesterol efflux: 
studies with transgenic mice. Arterioscler Thromb Vasc Biol 18: 1417-1423.

Chiu SW, Jakobsson E, Subramaniam S, Scott L (1999) Combined Monte Carlo and molecular dynamics simulation of fully hydrated dioleyl and palmitoyl-oleyl phosphatidylcholine lipid bilayers. Biophys J 77: 24622469.

Collet X, Perret B, Simard G, Raffai E, Marcel YL (1991). Differential effects of lecithin and cholesterol on the immunoreactivity and conformation of apolipoprotein A-I in high density lipoproteins. J Biol Chem 266: 91459152.

Colvin PL, Parks JS (1999) Metabolism of high density lipoprotein subfractions. Curr Opin Lipidol 10: 309-314.

Davidson WS, Rodriguez WV, Lund-Katz S, Johnson WJ (1995) Effects of acceptor particle size on the efflux of cellular free cholesterol. J Biol Chem 270: 17106-17113.

Demeler B, Saber H (1998) Determination of molecular parameters by fitting sedimentation data to finite-element solutions of Lamm equation. Biophys J 74: 444-454.

Dergunov AD, Dobrestov GE, Visvikis S, Siest G (2001) Protein-lipid interactions in reconstituted high density lipoproteins: apolipoprotein and cholesterol influence. Chem Phys Lipids 113: 67-82.

Desrumaux C, Athias A, Masson D, Gambert P, Lallemant C, Lagrost L (1998) Influence of the electrostatic charge of lipoprotein particles on the activity of human plasma phospholipid transfer protein. I Lipid Res 39: 131-142.

Dory L, Sloop CH, Roheim PS (1986) Interstitial fluid (peripheral lymph) lipoproteins. Methods Enzymol 129: 660-678.

Duverger N, Rader D, Duchateau P, Fruchart JC, Castro G, Brewer HB (1993) Biochemical characterization of the three major subclasses of lipoprotein A-I preparatively isolated from human plasma. Biochemistry 32: 12372-12379.

Fielding PE, Fielding CJ (1980) A cholesteryl ester transfer complex in human plasma. Proc Natl Acad Sci USA 77: 3327-3330.

Fielding CJ, Fielding PE (1981) Evidence for a lipoprotein carrier in human plasma catalyzing sterol efflux from cultured fibroblasts and its relationship to lecithin: cholesterol acyltransferase. Proc Natl Acad Sci USA 78: 3911-3914.

Fielding PE, Kawano M, Catapano AL, Zoppo A, Marcovina S, Fielding CJ (1994) Unique epitope of apolipoprotein A-I expressed in pre-beta-1 high density lipoprotein and its role in the catalyzed efflux of cellular cholesterol. Biochemistry 33: 6981-6985.

Giddings JC (1991) Unified Separation Science, pp 155-156. Wiley, New York.

Gillotte KL, Davidson WS, Lund-Katz S, Rothblat GH, Phillips MC (1998) Removal of cellular cholesterol by pre- $\beta$-HDL involves plasma membrane microsolubilization. I Lipid Res 39: 1918-1928.

Glomset JA (1968) The plasma lecithin:cholesterol acyltransferase reaction. J Lipid Res 9: 155-167.

Handwerger S, Datta G, Richardson B, Schmidt CM, Siddiqi T, Turzai L, Anantharamaiah GM (1999) Pre- $\beta$ HDL stimulates placental lactogen release from human trophoblast cells. Am J Physiol 276 Pt1: E384-389.

Havel RJ, Eder HA, Bragdon JH (1955) The distribution and chemical composition of ultracentrifugally separated lipoproteins in human serum. J Clin Invest 34: 1345-1353.

Haynes MP, Phillips MC, Rothblat GH (2000) Efflux of cholesterol from different cellular pools. Biochemistry 39: 4508-4517.

Ishida BY, Frolich J, Fielding CJ (1987) Prebeta-migrating high density lipoprotein: quantitation in normal and hyperlipidemic plasma by solid phase radioimmunoassay following electrophoretic transfer. I Lipid Res 28: 778-786.

Jaspard B, Collet X, Barbaras R, Manent J, Vieu C, Parinaud J, Chap H, Perre B (1996) Biochemical characterization of pre- $\beta_{1}$-HDL from human ovarian follicular fluid: evidence for the presence of a lipid core. Biochemistry 35: 1352-1357.

Jonas A, Wald JH, Harms Toohill KL, Krul E, Kezzdy KE (1990) Apolipoprotein A-I structure and lipid properties in homogeneous, reconstituted spherical and discoidal high density lipoprotein. J Biol Chem 265: 22123 22129.

Koln AE, Segrest JP, Harvey SC (2002) Molecular dynamics simulation on discoidal HDL particles suggest a mechanism for rotation in the apoA-I belt model. J Mol Biol 324: 703-721.

Lamm O (1929) Die Differentialgleichung der Ultracentrifugierung. Ark Mat Astron Fys 21B: 1-4.

Li Z, McNamara JR, Ordovas JM, Schaefer EJ (1994) Analysis of high density lipoproteins by a modified gradient gel electrophoresis method. J Lipid Res 35: 1698-1711.

Lusa S, Jauhainen M, Mesto J, Somerharju P, Ehnholm C (1996) The mechanism of human plasma phospholipid transfer protein-induced enlargement of high density lipoprotein particles: evidence for particle fusion. Biochem J 313: 275-282.

Marcovina S, Fantappie S, Zoppo A, Franceschini G, Catapano AL (1990) Immunochemical characterization of six monoclonal antibodies to human apolipoprotein A-I: epitope mapping and expression. J Lipid Res 31: 375-384.

Miller NE (1990) High density lipoprotein metabolism and its role in lipid transport. Eur Heart J 11 Suppl H: 1-3.

Murzyn K, Rog T, Jezierski G, Takaoka Y, PasenkiewiczGierula M (2001) Effects of phospholipid unsaturation on the membrane/water interface: a molecular simulation study. Biophys J 81: 170-183.

Nanjee MN, Brinton EA (2000) Very small apolipoprotein A-I-containing particles from human plasma: isolation and quantification by high-performance size-exclusion chromatography. Clin Chem 46: 207-223.

Ohta T, Saku K, Takata K, Nakamura R, Ikeda Y, Matsuda I (1995) Different effects of subclasses of HDL containing apoA-I but not apoA-II (LpA-I) on cholesterol esterification in plasma and net cholesterol efflux from foam cells. Arterioscler Thromb Vasc Biol 15: 956-962.

Oram JF, Albers JJ, Cheung MC, Bierman EL (1981) The effects of subfractions of high density lipoprotein on cholesterol efflux from cultured fibroblasts. Regulation of low density lipoprotein receptor activity. J Biol Chem 256: 8348-8356.

Patsch W, Schonfeld G, Gotto AM, Patsch JR (1980) Characterization of human high density lipoproteins by zonal ultracentrifugation. J Biol Chem 255: 3178-3185.

Petit E, Ayrault-Jarrier M, Pastier D, Robin H, Polonovski J, Aragon I, Hervaud E, Pau B (1987) Monoclonal antibodies to human apolipoprotein A-I: characterization and application as structural probes for apolipoprotein A-I and high density lipoprotein. Biochim Biophys Acta 919: $287-296$

Pio F, De Loof H, Vu Dac N, Clavy V, Fruchart JC, Rosseneu M (1988) Immunochemical characterization of two antigenic sites on human apolipoprotein A-I: localization and lipid modulation of these epitopes. Biochim Biophys Acta 959: 160-168.

Phillips JC, Wriggers W, Li Z, Jonas A, Schulten K (1997) Prediction of the structure of apolipoprotein A-I in re- 
constituted high-density lipoprotein disks. Biophys J 73: 2337-2346

Rog T, Murzyn K, Pasenkiewicz-Gierula M (2003) Molecular dynamics simulations of charged and neutral lipid bilayers: treatment of electrostatic interactions. Acta Biochim Polon 50: 789-798.

Rothblat GH, de la Llera-Moya M, Atger V, Kellner-Weibel G, Williams DL, Phillips MC (1999) Cell cholesterol efflux: integration of old and new observations provides new insights. J Lipid Res 40: 781-796.

Rothe GM (1991) Determination of the size, isomeric nature and net charge of enzymes by pore gradient gel electrophoresis. In Advances in Electrophoresis. Chrambach A, Dunn MJ, Radola BJ, eds, vol 4, pp 251-358. $\mathrm{VCH}$, Weinheim.

Rothe GM (1994) Electrophoresis of Enzymes, Laboratory Methods, pp 104-119. Springer Verlag, Berlin.

Saku K, von Eckardstein A, Zhang B, Liu R, Jimi S, Ou J, Ohta T, Assmann G, Arakawa A (1999) In vivo kinetics of human apolipoprotein A-I variants in rabbits. Eur J Clin Invest 29: 196-203.

Schwartz FT, Paltauf F (1976) Studies on the interaction of cholesterol with diester- and dietherlecithin. Chem Phys Lipids 17: 423-434.

Sparks DL, Phillips MC (1992) Quantitative measurement of lipoprotein surface charge by agarose gel electrophoresis. J Lipid Res 33: 123-130.

Sparks DL, Phillips MC, Lund-Katz S (1992a) The conformation of apolipoprotein A-I in discoidal and spherical recombinant high density lipoprotein particles. ${ }^{13} \mathrm{C}$ NMR studies of lysine ionization behavior. J Biol Chem 267: 25830-25838.
Sparks DL, Lund-Katz S, Phillips MC (1992b) The charge and structural stability of apolipoprotein A-I in discoidal and spherical recombinant high density lipoprotein particles. J Biol Chem 267: 25839-25847.

Sparks DL, Anantharamaiah GM, Segrest JP, Phillips MC (1995) Effect of the cholesterol content of reconstituted LpA-I on lecithin:cholesterol acyltransferase activity. J Biol Chem 270: 5151-5157.

Sparks DL, Frank PG, Braschi S, Noville TA, Marcel YL (1999) Effect of apolipoprotein A-I lipidation on the formation and function of pre-beta and alpha-migrating LpA-I particles. Biochemistry 38: 1727-1735.

Sviridov D, Miyazaki O, Theodore K, Hoang A, Fukamachi I, Nestel P (2002) Delineation of the role of pre- $\beta_{1}$ HDL in cholesterol efflux using isolated pre- $\beta_{1}$-HDL. Arterioscler Thromb Vasc Biol 22: 1482-1488.

Tricerri A, Corsico B, Toledo JD, Garda HA, Brenner RR (1998) Conformation of apolipoprotein A-I in reconstituted lipoprotein particles and particle-membrane interaction: effect of cholesterol. Biochim Biophys Acta 1391: $67-78$.

Tristram-Nagle S, Petrache HI, Nagle J (1998) Structure and interactions of fully hydrated dioleoylphosphatidylcholine bilayers. Biophys J 75: 917-925.

Tu H, Klein ML, Tobias DJ (1998) Constant-pressure molecular dynamics investigation of cholesterol effects in a dipalmitoylphosphatidylcholine bilayer. Biophys J 75: 2147-2156.

Vitello LB, Scanu AM (1976) Studies on human serum high density lipoproteins. Self association of apolipoprotein A-I in aqueous solution. J Biol Chem 251: 1131-1136. 